\title{
An infrared and raman spectroscopic study of crystalline trans-crotonic acid
}

\author{
Rui Fausto \\ Departamento de Quimica, Universidade de Coimbra, P-3049 Coimbra, Portugal
}

Received 21 June 1995; accepted in final form 8 September 1995

\begin{abstract}
Trans-crotonic acid was studied by FT-IR and Raman spectroscopies. A detailed assignment of the vibrational spectra in the crystalline phase (where dimeric units exist) is reported and discussed in comparison with that of the monomer isolated in a low temperature argon matrix. Results of molecular orbital calculations (semiempirical AMl and ab initio 6-3 $1 \mathrm{G}^{*}$ ) on both monomeric and dimeric trans-crotonic acid are also presented and used to help the interpretation of the spectroscopic data.
\end{abstract}

Keywords: Trans-crotonic acid; Molecular structure; Infrared spectrum; Raman spectrum; Molecular orbital calculations

\section{Introduction}

The low temperature FT-IR vibrational spectra of the monomer of trans-crotonic acid (CA) isolated in noble gas matrices were reported recently [1]. With results of ab initio SCF-MO calculations undertaken using the $6-31 \mathrm{G}^{*}$ basis set, the experimental data [1] enabled a detailed assignment of the spectra of the two experimentally observed conformers of CA (Fig. 1): the more stable s-cis conformer (having both $\mathrm{O}=\mathrm{C}-\mathrm{O}-\mathrm{H}$ and $\mathrm{C}=\mathrm{C}-\mathrm{C}=\mathrm{O}$ dihedral angles equal to $0^{\circ}$ ) and the slightly less stable s-trans form (where $\mathrm{O}=\mathrm{C}$ $\mathrm{O}-\mathrm{H}$ and $\mathrm{C}=\mathrm{C}-\mathrm{C}=\mathrm{O}$ are $0^{\circ}$ and $180^{\circ}$, respectively). In addition to the vibrational data, other relevant molecular properties for these conformers were also determined and used to shed light on the main intramolecular interactions present. In particular, it was shown that the most important factors determining the relative energy of the conformers are (i) mesomerism within the carboxylate group $\left(\mathrm{CH}_{3} \mathrm{CH}=\mathrm{CHC}(=\mathrm{O}) \mathrm{O}-\mathrm{H} \leftrightarrow\right.$ $\left.\mathrm{CH}_{3} \mathrm{CH}=\mathrm{CHC}\left(-\mathrm{O}^{-}\right)=\mathrm{O}^{+}-\mathrm{H}\right)$, (ii) steric repulsions between the $\mathrm{CH}_{3} \mathrm{CH}=\mathrm{CH}$ moiety and the oxygen atoms and (iii) mesomerism involving both $\mathrm{C}=\mathrm{C}$ and $\mathrm{C}=\mathrm{O}$ double bonds $\mathrm{CH}_{3} \mathrm{CH}=\mathrm{CH}-\mathrm{C}(=\mathrm{O}) \mathrm{OH} \leftrightarrow \mathrm{CH}_{3} \mathrm{C}^{+} \mathrm{H}-\mathrm{CH}=\mathrm{C}(-$ $\left.\left.\mathrm{O}^{-}\right) \mathrm{OH}\right)$. The first two factors were found to favour the most stable s-cis form, while the third factor favours the s-trans conformer [1].

In crystals, $\mathbf{C A}$ forms cyclic hydrogen-bonded dimers. Their structure has been determined by X-ray diffraction [2] and it was shown that both molecules forming the dimeric unit adopt the s-cis conformation. In addition, the dimers were found to pack in the crystal as shown schematically in Fig. 2, exhibiting a $\mathrm{C}_{\alpha}-\mathrm{H} \cdots \mathrm{O}=$ interdimer contact with a $\mathrm{C}=\mathrm{O} \cdots \mathrm{H}^{\prime}$ angle of $\approx 130^{\circ}[3,4]$.

However, to the best of our knowledge, no detailed spectroscopic studies have been previously 


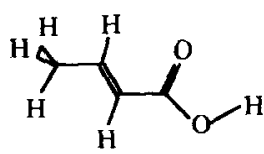

s-cis

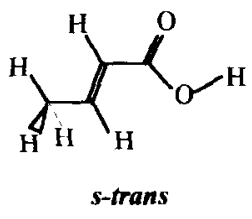

Fig. 1. Experimentally observed conformers of monomeric trans-crotonic acid [1].

undertaken on crystalline CA, despite a series of studies that have looked at individual spectral regions (in particular the carbonyl stretching region) $[5,6]$. Furthermore, no theoretical predictions of either the molecular structure or vibrational spectra of the CA dimer have been reported. In this study, we report a detailed infrared and Raman spectroscopic study of CA, in the crystalline phase, at room temperature. A systematic comparison is made with the results for the monomeric forms [1], to analyse the effects of both hydrogen bonding and crystal packing on the molecular properties. Finally, 6-31G* ab initio and AM1 semiempirical molecular orbital calculations have been carried out on both the dimer and the monomer of CA, and the theoretical spectra compared with the experimental data to help interpret the spectroscopic results.

\section{Experimental and computational methods}

Trans-crotonic acid ( $99+\%$ purity) was obtained from Fluka, recrystallized from benzene and dried in a vacuum disiccator over $\mathrm{CaCl}_{2}$.

Infrared spectra were obtained as $\mathrm{KBr}$ pellets

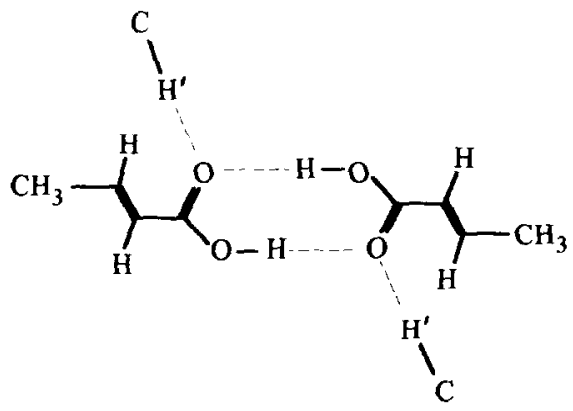

Fig. 2. Schematic representation of the packing motif found in crystalline $\mathrm{CA}$, showing $\mathrm{C}_{\alpha}-\mathrm{H} \cdots \mathrm{O}=$ interdimer contacts [4]. using a Nicolet FTIR 800 system equipped for the $4000-400 \mathrm{~cm}^{-1}$ region with a germanium on CsI beam splitter and a deuterated triglycine sulphide (DTGS) detector with CsI windows, using 32 scans with the spectral resolution $1 \mathrm{~cm}^{-1}$.

Raman spectra were obtained using a SPEX 1403 double monochromator spectrometer (focal distance $0.85 \mathrm{~m}$, aperture $f / 7.8$ ), equipped with holographic gratings with 1800 grooves $\mathrm{mm}^{-1}$ (ref. 1800-1SHD). The $514.5 \mathrm{~nm}$ argon laser (Spectra-Physics, model 164-05) line, adjusted to provide $220 \mathrm{~mW}$ power at the sample, was used as excitation radiation. Detection was effected using a thermoelectrically cooled Hamamatsu R928 photomultiplier. Spectra were recorded using increments of $1 \mathrm{~cm}^{-1}$ and integration times of $1 \mathrm{~s}$. Under these conditions, the estimated errors in wavenumbers are $\pm 1 \mathrm{~cm}^{-1}$.

The molecular orbital calculations were performed both at the ab initio 6-31G* [7] and semiempirical (AM1 [8]) levels of theory, using the GAUSSIAN 92/DFT program package [9] running on a DEC ALPHA 7000 computer. Molecular geometries were fully optimized by the force gradient method using Berny's algorithm [10]. The largest residual coordinate forces were always less than $3 \times 10^{-4}$ hartree bohr $^{-1}$ (1 hartree = $2625.5001 \mathrm{~kJ} \mathrm{~mol}^{-1} ; \quad$ bohr $\left.=5.29177 \times 10^{-11} \mathrm{~m}\right)$ or hartree $\mathrm{rad}^{-1}$, for bond stretches and angle bends, respectively. The $6-31 \mathrm{G}^{*}$ ab initio calculated wavenumbers of the dimer were scaled down using the scaling factors previously obtained for the monomer (in-plane modes; $\nu_{i}^{\text {scaled }}(6-$ $\left.31 \mathrm{G}^{*}\right)=0.870 \nu_{i}^{\text {calc }}+25.8$; out-of-plane modes: $\nu_{i}^{\text {scaled }}\left(6-31 \mathrm{G}^{*}\right)=0.882 \nu_{i}^{\text {calc }}+2.5$ [1]). In turn, AM 1 calculated wavenumbers for each individual vibration of the monomer were corrected by means of a simple additive term $\left(\nu_{i}^{\text {scaled }}(\right.$ AM1 $)=$ $\left.\nu_{i}^{\text {obs }}+\lambda_{i}\right)$. This set of correction factors was then applied to the corresponding calculated wavenumbers for the vibrations of the dimer.

\section{Results and discussion}

The calculated molecular geometries, relative energies and electric dipole moments for the monomeric species (s-cis and s-trans) and dimer of CA 
are presented in Table 1. The results obtained at the semiempirical (AM1) level of theory show a very good general agreement with the higher level $\mathrm{ab}$ initio 6-31G* results. In particular, the AM1 calcu- lations reproduce properly (i) the relative order of stability of the two experimentally observed conformers of monomeric $\mathbf{C A}$, (ii) the relative magnitude of their electric dipole moments (the

Table 1

6-31G* and AMI calculated optimized geometries, rotational constants, energies and electric dipole moments for the experimentally observed monomeric forms (Ar matrix [1]) and dimer unit (crystal) of $\mathbf{C A}^{\mathbf{a}}$

\begin{tabular}{|c|c|c|c|c|c|c|}
\hline \multirow[t]{2}{*}{ Parameter } & \multicolumn{3}{|c|}{ ab initio $6-31 G^{*}$} & \multicolumn{3}{|c|}{ Semiempirical (AMI) } \\
\hline & s-cis & s-trans & dimer & s-cis & s-trans & dimer \\
\hline $\mathrm{C}=\mathrm{O}$ & 119.15 & 119.05 & 120.55 & 123.72 & 123.64 & 124.10 \\
\hline $\mathrm{C}-\mathrm{O}$ & 133.13 & 133.37 & 130.77 & 136.62 & 136.74 & 135.81 \\
\hline $\mathrm{C}_{\alpha}-\mathrm{C}$ & 147.83 & 147.68 & 147.75 & 146.24 & 146.20 & 146.37 \\
\hline $\mathrm{C}=\mathrm{C}$ & 132.28 & 132.29 & 132.28 & 133.98 & 133.89 & 133.95 \\
\hline $\mathrm{C}-\mathrm{C}$ & 149.76 & 149.86 & 149.74 & 147.38 & 147.44 & 147.42 \\
\hline $\mathrm{C}_{\alpha}-\mathrm{H}$ & 107.44 & 107.45 & 107.45 & 110.14 & 110.28 & 110.13 \\
\hline $\mathrm{C}_{\beta}-\mathrm{H}$ & 107.68 & 107.61 & 107.67 & 110.60 & 110.56 & 110.60 \\
\hline $\mathrm{C}-\mathrm{H}_{i, p}$ & 108.33 & 108.33 & 108.32 & 111.76 & 111.76 & 111.77 \\
\hline $\mathrm{C}-\mathrm{H}_{o \text { op }}$ & 108.64 & 108.63 & 108.64 & 111.97 & 111.97 & 111.97 \\
\hline $\mathrm{O}-\mathrm{H}$ & 95.20 & 95.18 & 96.61 & 97.12 & 97.12 & 97.65 \\
\hline $\mathrm{O}=\mathrm{C}-\mathrm{O}$ & 122.08 & 121.90 & 123.36 & 116.20 & 115.99 & 117.00 \\
\hline $\mathrm{C}-\mathrm{C}=\mathrm{O}$ & 126.07 & 123.79 & 124.00 & 129.76 & 128.15 & 128.71 \\
\hline $\mathrm{C}-\mathrm{C}-\mathrm{O}$ & 111.85 & 114.31 & 112.64 & 114.04 & 115.86 & 114.29 \\
\hline $\mathrm{H}-\mathrm{C}_{n}-\mathrm{C}$ & 116.93 & 113.88 & 116.53 & 115.49 & 113.58 & 115.41 \\
\hline $\mathrm{C}=\mathrm{C}_{\alpha}-\mathrm{C}$ & 120.53 & 124.01 & 120.94 & 121.32 & 123.56 & 121.36 \\
\hline $\mathrm{H}-\mathrm{C}_{\beta}=\mathrm{C}$ & 117.89 & 118.90 & 117.98 & 120.43 & 120.64 & 120.42 \\
\hline $\mathrm{C}-\mathrm{C}_{\beta}-\mathrm{C}$ & 125.10 & 124.62 & 125.05 & 123.60 & 123.53 & 123.61 \\
\hline $\mathrm{C}-\mathrm{O}-\mathrm{H}$ & 107.88 & 107.55 & 110.70 & 109.21 & 109.21 & 109.96 \\
\hline $\mathrm{H}_{i, p}-\mathrm{C}-\mathrm{C}$ & 111.87 & 111.82 & 111.89 & 112.17 & 112.18 & 112.16 \\
\hline $\mathbf{H}_{o, 0 . p}-\mathbf{C}-\mathbf{C}$ & 110.35 & 110.38 & 110.34 & 109.77 & 109.78 & 109.79 \\
\hline $\mathrm{C}-\mathrm{C}(=\mathrm{O})-\mathrm{O}$ & 180.00 & 180.00 & 180.00 & 180.00 & 180.00 & 180.00 \\
\hline $\mathrm{H}-\mathrm{C}-\mathrm{C}=\mathrm{O}$ & 180.00 & 0.00 & 180.00 & 180.00 & 0.00 & 180.00 \\
\hline $\mathrm{C}=\mathrm{C}-\mathrm{C}=\mathrm{O}$ & 0.00 & 180.00 & 0.00 & 0.00 & 180.00 & 0.00 \\
\hline $\mathrm{H}-\mathrm{C}=\mathrm{C}-\mathrm{C}$ & 0.00 & 0.00 & 0.00 & 0.00 & 0.00 & 0.00 \\
\hline $\mathrm{C}-\mathrm{C}=\mathrm{C}-\mathrm{C}$ & 180.00 & 180.00 & 180.00 & 180.00 & 180.00 & 180.00 \\
\hline $\mathrm{O}=\mathrm{C}-\mathrm{O}-\mathrm{H}$ & 0.00 & 0.00 & 0.00 & 0.00 & 0.00 & 0.00 \\
\hline $\mathrm{H}_{i, p}-\mathrm{C}-\mathrm{C}=\mathrm{C}$ & 0.00 & 0.00 & 0.00 & 0.00 & 0.00 & 0.00 \\
\hline $\mathrm{H}_{\text {o. o.p. }}-\mathrm{C}-\mathrm{C}=\mathrm{C}$ & 121.74 & 120.94 & 120.99 & 120.67 & 120.66 & 120.66 \\
\hline$=\mathrm{O} \cdots \mathrm{H}$ & - & - & 181.97 & - & - & 209.19 \\
\hline $\mathrm{C}=\mathrm{O} \cdots \mathrm{H}$ & - & - & 129.18 & - & - & 136.94 \\
\hline$=\mathrm{O} \cdots \mathrm{H}-\mathrm{O}$ & - & - & 176.74 & - & - & 176.05 \\
\hline A & 11376.27 & 10140.44 & 4193.64 & 10151.35 & 10057.08 & 3962.86 \\
\hline B & 1917.28 & 1950.79 & 251.40 & 1876.38 & 1917.74 & 230.16 \\
\hline $\mathrm{C}$ & 1634.36 & 1652.51 & 237.87 & 1600.26 & 1627.80 & 218.15 \\
\hline$\Delta E^{b}$ & - & 2.838 & -65.990 & - & 1.706 & -25.923 \\
\hline$|\mu|$ & 1.957 & 2.899 & 0.000 & 0.911 & 1.164 & 0.000 \\
\hline
\end{tabular}

\footnotetext{
${ }^{\text {a }}$ Bond lengths in pm, angles in degrees, rotational constants in $\mathrm{MHz}$, energies in $\mathrm{kJ} \mathrm{mol}^{-1}$, dipole moments in Debyes $\left(1 \mathrm{D}=3.33564 \times 10^{-30} \mathrm{C.m}\right)$.

${ }^{\mathrm{b}}$ Relative energies: $E_{\mathrm{s}-\mathrm{trans}}-E_{\mathrm{s}-\mathrm{cis}}$ or $E_{\mathrm{dimer}}-2 \times E_{\mathrm{s}-\mathrm{cis}}$. The ab initio 6-31G* and AM1 total energies for the s-cis monomeric form are, -304.6963417 and -0.1392648 hartrees $\left(1\right.$ hartree $\left.=2625.5001 \mathrm{~kJ} \mathrm{~mol}^{-1}\right)$, respectively.
} 
calculated $\mu_{\mathrm{s}-\text { trans }} / \mu_{\text {s-cis }}$ ratio is 1.48 and 1.28 at the 6-31G* ab initio and AM1 levels of theory, respectively; AM1 however, systematically underestimates the results compared with the ab initio data), (iii) most of the changes in the geometrical parameters associated with the $\mathrm{s}$-cis $\rightarrow \mathrm{s}$-trans isomerization and (iv) the changes in geometries associated with the dimer formation. In relation to the geometrical changes associated with $\mathrm{s}$-cis $\rightarrow$ s-trans isomerization, the $\mathrm{C}-\mathrm{O}$ bond becomes longer due to the reduced importance of the mesomerism within the carboxylate group in the s-trans form, the $\mathrm{C}_{\alpha}-\mathrm{C}$ bond becomes shorter due to an increased importance of the mesomerism involving both $\mathrm{C}=\mathrm{C}$ and $\mathrm{C}=\mathrm{O}$ double bonds in this conformer, and both the $\mathrm{C}-\mathrm{C}=\mathrm{O}$ and $\mathrm{H}-\mathrm{C}_{x}-\mathrm{C}$ angles reduce while the $\mathrm{C}-\mathrm{C}-\mathrm{O}, \mathrm{C}=\mathrm{C}_{\alpha} \quad \mathrm{C}$ and $\mathrm{H}-\mathrm{C}_{\beta}=\mathrm{C}$ angles increase due to the greater importance of the destabilizing steric repulsions between the $\mathrm{CCH}_{3} \mathrm{H}=\mathrm{CH}$ moiety and the $-\mathrm{O}$ - atom in the s-trans form, when compared with the $\mathrm{CCH}_{3} \mathrm{H}=\mathrm{CH} / \mathrm{O}=$ repulsions in the s-cis form. On the other hand, as can be anticipated, geometrical changes associated with dimer formation occur essentially in the carboxyl moiety, which is directly involved in the hydrogen-bonding (see Table 1): the $\mathrm{C}=\mathrm{O}$ and $\mathrm{C}-\mathrm{O}$ bonds become respectively longer and shorter (i.e., the two $\mathrm{CO}$ bonds become more similar), the $\mathrm{O}-\mathrm{H}$ bond becomes longer, and both the $\mathrm{O}=\mathrm{C}-\mathrm{O}$ and $\mathrm{C}-\mathrm{O}-\mathrm{H}$ angles increase in order to permit the establishment of more efficient $=\mathrm{O} \cdots \mathrm{H}-\mathrm{O}$ hydrogen bonds. The change in the $\mathrm{O}=\mathrm{C} \mathrm{O}$ angle is essentially compensated by a decrease of the $\mathrm{C}-\mathrm{C}=\mathrm{O}$ angle. It should, however, be pointed out that both the geometric and energetic results clearly indicate that the $6-31 \mathrm{G}^{*}$ calculations predict a considerably stronger hydrogen bond within the dimer of $\mathbf{C A}$ than AM1. Indeed, the calculated percent changes in the $\mathrm{C}=\mathrm{O}, \mathrm{C}-\mathrm{O}$ and $\mathrm{O}-\mathrm{H}$ bond lengths upon dimer formations are $1.17 \%,-1.17 \%$ and $1.48 \%$ $\left(6-31 \mathrm{G}^{*}\right)$ and $0.31 \%,-0.59 \%$ and $0.54 \%$ (AM1), respectively, while the $=\mathrm{O} \cdots \mathrm{H}$ hydrogen bond distance is predicted to be considerably shorter by the $6-31 G^{*}$ calculations than by the AM1 method (181.97 vs. $209.19 \mathrm{pm}$ ) and the calculated energy of dimer formation (measured as $E_{\text {dimer }}-2 \times$ $E_{\text {monomer }}$ ) is significantly larger at the ab initio than at the semiempirical level $(-65.990$ vs. $\left.-25.923 \mathrm{~kJ} \mathrm{~mol}^{-1}\right)$. The $=\mathrm{O} \cdots \mathrm{H}-\mathrm{O}$ hydrogen

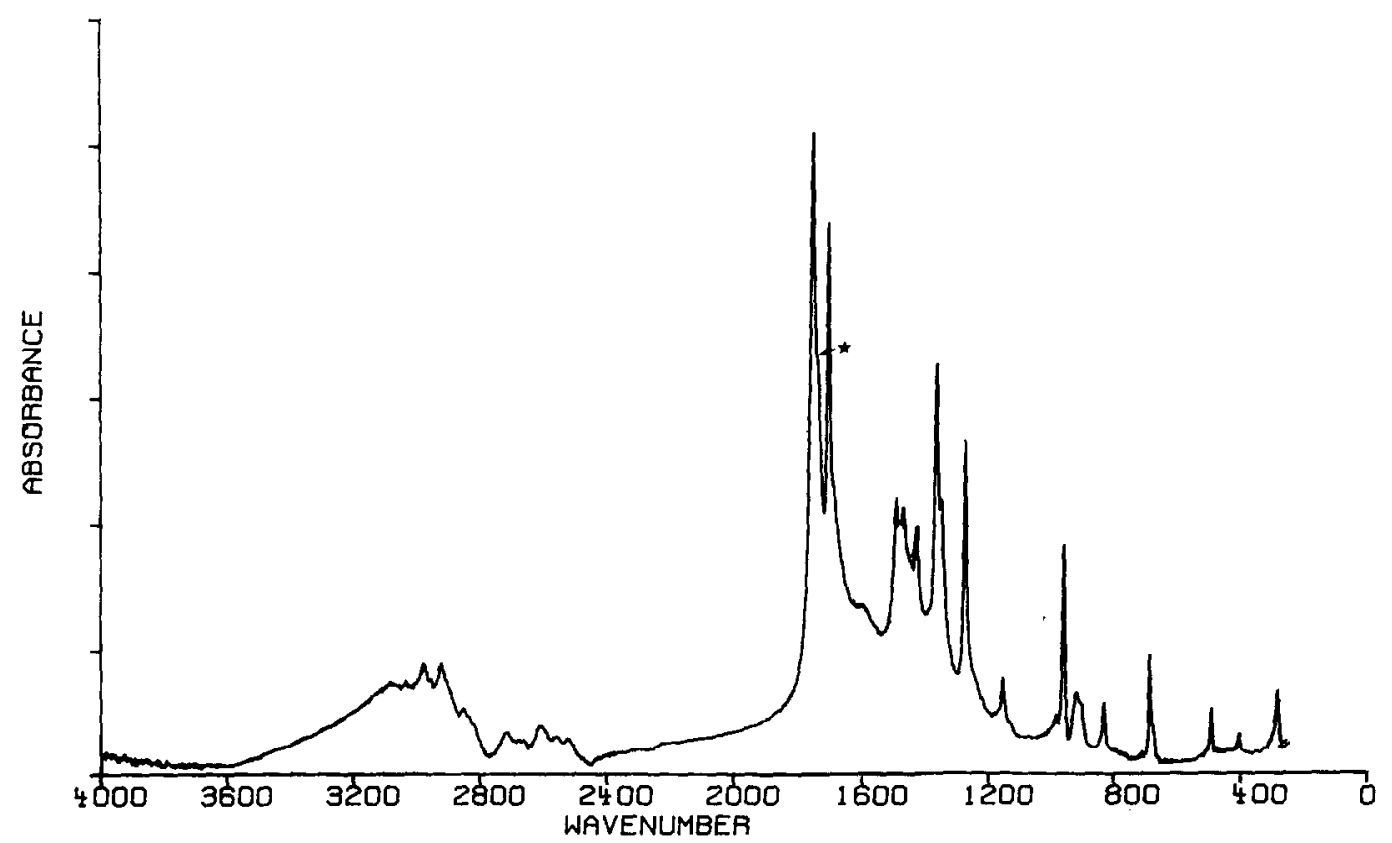

Fig. 3. Infrared spectrum of crystalline $\mathrm{CA}$ at room temperature (wavenumbers in $\mathrm{cm}^{-1}$ ). The band marked with an asterisk was assigned to the $\nu \mathrm{C}=\mathrm{O}$ mode of $\mathrm{B}_{\mathrm{g}}$ symmetry, which should be non-active in infrared if the selection rules hold rigorously. 


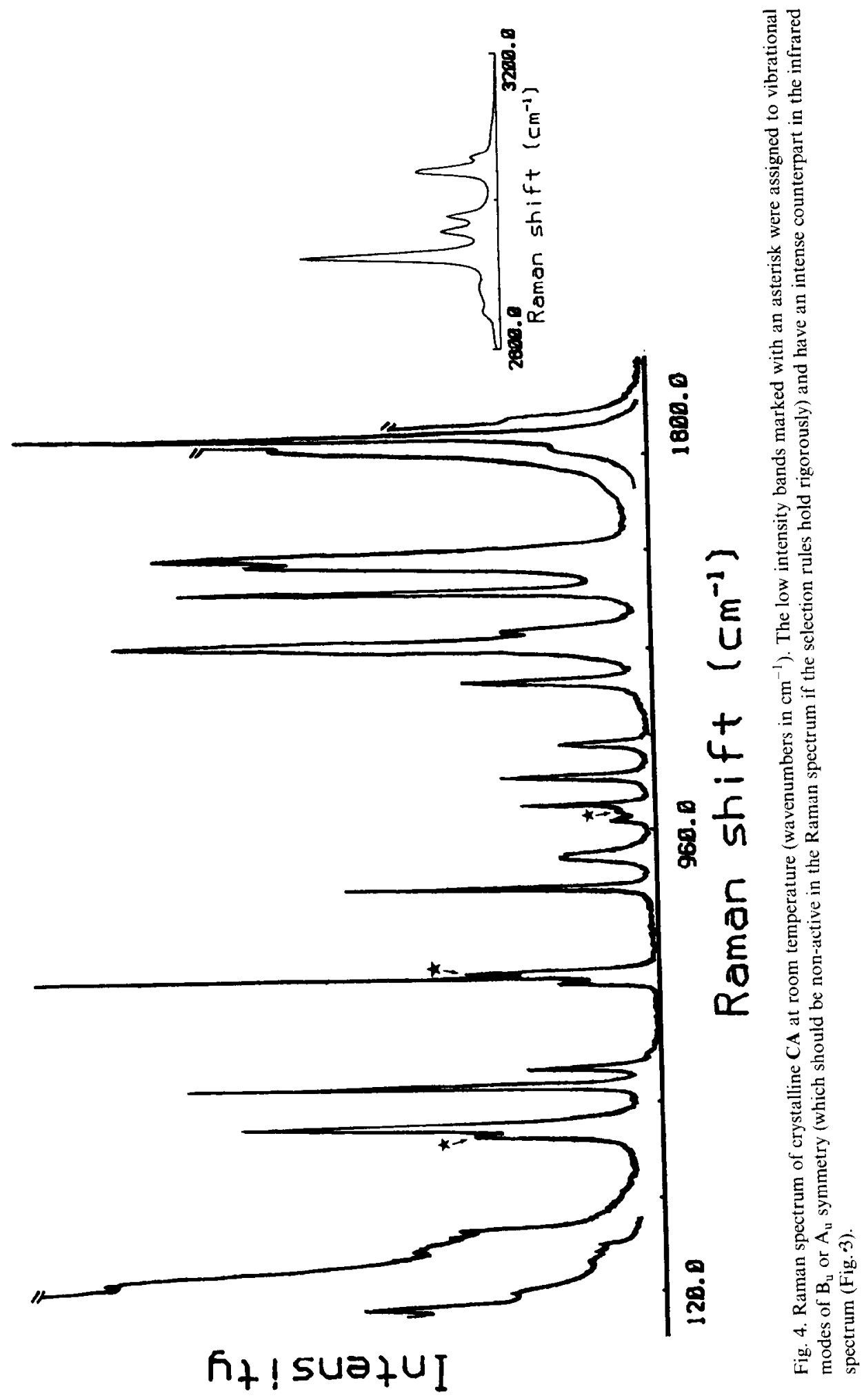


Table 2

Experimental and calculated vibrational wavenumbers and intensities for trans-crotonic acid monomer $(\mathbf{T}-\mathbf{c c} \text { form })^{\mathrm{a}}$

\begin{tabular}{|c|c|c|c|c|c|c|c|c|c|c|}
\hline \multirow[t]{2}{*}{$\begin{array}{l}\text { Approximate } \\
\text { Description }\end{array}$} & \multirow[t]{2}{*}{ Symmetry } & \multicolumn{2}{|c|}{$\begin{array}{l}\text { Exp. (IR, Ar } \\
\text { matrix) [1] }\end{array}$} & \multicolumn{3}{|c|}{ Calc. (AM1) } & \multicolumn{4}{|c|}{ Calc. $\left(6-31 \mathrm{G}^{*}\right)[1]$} \\
\hline & & $\nu^{\mathrm{gc} \mathrm{b}}$ & $I^{\text {Total c }}$ & $\nu^{\text {Calc }}$ & $I^{\mathrm{d}}$ & $\Delta \nu^{c}$ & $\nu^{\text {Calc }}$ & $I^{\mathrm{d}}$ & $\nu^{\text {scaled } \mathrm{f}}$ & $\Delta \nu^{\mathrm{e}}$ \\
\hline$\nu \mathrm{O}-\mathrm{H}$ & $A^{\prime}$ & 3578 & 5.5 & 3431 & 11.6 & 147 & 4060 & 7.7 & 3562 & 16 \\
\hline$\nu \mathrm{C}_{\alpha}-\mathrm{H}$ & $A^{\prime}$ & n.o. & & 3181 & 5.2 & $(-107)$ & 3388 & 0.4 & 3074 & - \\
\hline$\nu \mathrm{C}_{\beta}-\mathrm{H}$ & $\mathbf{A}^{\prime}$ & 3015 & $<0.1$ & 3137 & 1.5 & -122 & 3369 & 0.2 & 3057 & -42 \\
\hline$\nu \mathrm{CH}_{3}$ as. & $A^{\prime}$ & 2990 & 0.6 & 3054 & 0.3 & -64 & 3288 & 1.3 & 2985 & 5 \\
\hline$\nu \mathrm{CH}_{3}$ as. & $A^{\prime \prime}$ & 2958 & 0.4 & 3041 & 0.6 & -83 & 3254 & 1.4 & 2967 & -9 \\
\hline$\nu \mathrm{CH}_{3} \mathrm{~s}$. & $A^{\prime}$ & 2929 & 0.3 & 3148 & 0.5 & -219 & 3202 & 1.4 & 2907 & 22 \\
\hline$\nu \mathrm{C}=\mathrm{O}$ & $A^{\prime}$ & 1757 & 19.1 & 2075 & 22.7 & -318 & 2007 & 22.1 & 1774 & -17 \\
\hline$\nu \mathrm{C}=\mathrm{C}$ & $\mathbf{A}^{\prime}$ & 1667 & 4.5 & 1872 & 8.4 & -205 & 1883 & 9.0 & 1666 & 1 \\
\hline$\delta \mathrm{CH}_{3}$ as. & $\mathbf{A}^{\prime}$ & 1448 & 4.6 & 1372 & 0.9 & 76 & 1629 & 1.9 & 1445 & 3 \\
\hline$\delta \mathrm{CH}_{3}$ as. & $A^{\prime \prime}$ & 1436 & 0.2 & 1380 & 0.4 & 56 & 1623 & 0.4 & 1434 & 2 \\
\hline$\delta \mathrm{CH}_{3} \mathrm{~s}$ & $A^{\prime}$ & 1377 & 0.8 & 1448 & 1.5 & -71 & 1565 & 0.2 & 1389 & -12 \\
\hline$\nu \mathrm{C}-\mathrm{O}+\delta \mathrm{C}-\mathrm{O}-\mathrm{H}$ & $A^{\prime}$ & 1359 & 2.6 & 1430 & 8.0 & -71 & 1532 & 8.8 & 1360 & -1 \\
\hline$\delta \mathrm{C}_{\beta}-\mathrm{H}$ & $A^{\prime}$ & 1306 & 0.7 & 1260 & 1.1 & 46 & 1445 & 1.0 & 1284 & 22 \\
\hline$\delta C_{\alpha}-\mathbf{H}$ & $A^{\prime}$ & 1271 & 0.9 & 1283 & 0.9 & -12 & 1412 & 1.1 & 1255 & 16 \\
\hline$\delta \mathrm{C}-\mathrm{O}-\mathrm{H}+1 / \mathrm{C}-\mathrm{O}$ & $A^{\prime}$ & 1147 & 18.0 & 1569 & 20.0 & -422 & 1312 & 21.8 & 1169 & -22 \\
\hline$\gamma \mathrm{CH}_{3}$ & $A^{\prime}$ & 1092 & 11.3 & 999 & 0.9 & 93 & 1216 & 2.1 & 1085 & 7 \\
\hline$\gamma \mathrm{CH}_{3}+\gamma \mathrm{C}_{\beta}-\mathrm{H}$ & $A^{\prime \prime}$ & n.o. & & 1085 & $<0.1$ & $(-21)$ & 1203 & 0.2 & 1064 & - \\
\hline$\gamma \mathrm{C}_{\alpha}-\mathrm{H}$ & $A^{\prime \prime}$ & 976 & 4.2 & 971 & 6.6 & 5 & 1107 & 2.2 & 979 & -3 \\
\hline$\nu \mathrm{C}-\mathrm{C}$ & $\mathbf{A}^{\prime}$ & 972 & 4.3 & 1323 & $<0.1$ & -351 & 1058 & 0.1 & 948 & 24 \\
\hline$\nu \mathrm{C}_{\alpha}-\mathrm{C}$ & $A^{\prime}$ & 890 & 0.8 & 1146 & 0.2 & -256 & 979 & 1.5 & 879 & 11 \\
\hline$\gamma \mathrm{C}_{3}-\mathrm{H}+\gamma \mathrm{CH}_{3}$ & $A^{\prime \prime}$ & 841 & 2.3 & 889 & $<0.1$ & -48 & 958 & 2.4 & 847 & -6 \\
\hline$\gamma \mathrm{C}-\mathrm{O}+\gamma \mathrm{C}=\mathrm{O}$ & $A^{\prime \prime}$ & 699 & 5.0 & 638 & 3.4 & 61 & 793 & 4.4 & 702 & -2 \\
\hline$\delta \mathrm{O}=\mathrm{C}-\mathrm{O}$ & $A^{\prime}$ & 648 & 4.0 & 665 & 2.8 & -17 & 718 & 3.3 & 651 & -3 \\
\hline$\gamma \mathbf{C}=\mathbf{O}+\tau \mathrm{C}-\mathrm{O}$ & $A^{\prime \prime}$ & 566 & 8.9 & 537 & 8.4 & 29 & 638 & 5.4 & 565 & 1 \\
\hline$\delta \mathrm{C}-\mathrm{C}=\mathrm{O}$ & $\mathrm{A}^{\prime}$ & 466 & 0.9 & 475 & 0.8 & -9 & 504 & 0.7 & 465 & 1 \\
\hline$\delta \mathrm{C}-\mathrm{C}_{\beta}=\mathrm{C}$ & $\mathrm{A}^{\prime}$ & n.o. & & 412 & 0.5 & $(-21)$ & 420 & 0.4 & 391 & - \\
\hline$\tau \mathrm{C}=\mathrm{C}$ & $A^{\prime \prime}$ & n.o. & & 185 & $<0.1$ & (13) & 222 & $<0.1$ & 198 & - \\
\hline$\tau \mathrm{C}-\mathrm{C}$ & $A^{\prime \prime}$ & n.o. & & 115 & $<0.1$ & $(71)$ & 208 & $<0.1$ & 186 & - \\
\hline$\delta \mathrm{C}=\mathrm{C}_{\alpha}-\mathrm{C}$ & $\mathbf{A}^{\prime}$ & n.o. & & 181 & 0.1 & $(20)$ & 201 & 0.1 & 201 & - \\
\hline$\tau \mathrm{C}_{\beta}-\mathrm{C}$ & $\mathbf{A}^{\prime \prime}$ & n.o. & & 69 & 0.1 & (31) & 110 & 0.1 & 100 & - \\
\hline
\end{tabular}

${ }^{a}$ Wavenumbers in $\mathrm{cm}^{-1} ; \nu$, stretching; $\delta$, bending; $\omega$, wagging; $\gamma$, rocking; $\tau$, torsion; n.o., not observed; s, symmetric; as., asymmetric.

${ }^{\mathrm{b}} \nu^{\mathrm{gc}}$ correspond to the wavenumbers of the gravity centres of the groups of bands ascribed to the same normal mode; they are calculated as $\nu^{\mathrm{gc}}=\Sigma_{i}\left(\nu^{\mathrm{obs}} \times I^{\mathrm{obs}}\right) / \Sigma_{i} I^{\mathrm{obs}}$, where $i$ is the number of total components of the group of bands.

${ }^{c}$ Experimental intensities presented are normalized values to the total intensity of all observed bands $\left(I=100 \times I^{\text {Obs }} / \Sigma_{i=1, n} I_{i}^{\text {obs }}\right.$, where $n$ is the number of observed infrared bands ascribed to this conformer). $I^{\text {Total }}$ is the total intensity of the bands ascribed to the same normal modc.

${ }^{d}$ Calculated intensities are normalized values to the total calculated intensity of all bands which have an experimentally observed counterpart. The non-normalised ab initio intensities $\left(\mathrm{km} \mathrm{mol}^{-1}\right)$ can be obtained by multiplying the values presented in the Table by 12.0 (AM1) or $16.8\left(6-31 G^{*}\right)$.

${ }^{\mathrm{e}} \Delta \nu=\nu^{\text {g.c. }}-\nu^{\text {calc }}$; values in parentheses correspond to $\Delta \nu=\nu^{\text {scaled }}-\nu^{\text {calc }}$.

The resulting scaled ab initio $\mathrm{C}-\mathrm{H}$ stretching wavenumbers were found to be considerably underestimated $(\%$ error $\approx 3-4)$. An additional correction factor (1.033) was then applied specifically to these vibrations, leading to a reduced error of less than $1 \%$. Such additional correction factor was obtained by linear regression, constrained by assuming a zero intercept and performed using all observed/scaled $\nu \mathrm{C}-\mathrm{H}$ wavenumbers for all experimentally observed conformers [1]. 
bond is predicted by both methods to be nearly linear and the $\mathrm{C}=\mathrm{O} \cdots \mathrm{H}$ angle to be $\approx 130-135^{\circ}$. Interestingly, this latter angle is similar to the reported $\mathrm{C}=\mathrm{O} \cdots \mathrm{H}^{\prime}$ angle associated with the interdimer $\mathrm{C}=\mathrm{O} \cdots \mathrm{H}^{\prime}-\mathrm{C}_{\alpha}$ contact in crystalline CA [2-4] (see also Fig. 2).

The infrared and Raman spectra of crystalline CA are presented in Figs. 3, 4. Table 2 summarizes the vibrational data for the monomer, in the s-cis conformation (experimental results were obtained for the monomer isolated in an Ar matrix, at $18 \mathrm{~K}$ [1]). The vibrational assignments made for the crystal are shown in Table 3.

The monomer belongs to the $\mathrm{C}_{\mathrm{s}}$ point group and thus, their 30 normal modes span the irreducible representations, $20 \mathrm{~A}^{\prime}+10 \mathrm{~A}^{\prime \prime}$, all modes being active both in Raman and infrared. In turn, the dimer has a $C_{2 h}$ symmetry and its Raman and infrared bands should be, in principle, non-coincident. Indeed, vibrations should occur as pairs, one in which each monomer unit vibrates in-phase with respect to the other (Raman active $A_{g}$ or $B_{g}$ normal modes), and one in which the monomer units vibrate out-of-phase with each other (infrared active $A_{u}$ and $B_{u}$ normal modes). However, in general vibrational sclection rules do not hold rigorously in hydrogen-bonded systems because the coupling between monomer units is relatively weak $[1,12]$ and, consequently, is not able in all cases to cause observable frequency differences between the in-phase and out-of-phase vibrations. In-phase vibrations may however still be expected to be stronger in the Raman spectrum than in the infrared spectrum, and out-of-phase vibrations to be stronger in the infrared. Out-ofphase vibrations are usually at a higher frequency than the in-phase, although there are often exceptions.

\subsection{Region above $1800 \mathrm{~cm}^{-1}$}

This is the spectral region where $\nu \mathrm{O}-\mathrm{H}$ and $\nu \mathrm{CH}$ $\left(\nu \mathrm{C}_{\alpha}-\mathrm{H}, \nu \mathrm{C}_{\beta}-\mathrm{H}\right.$ and the various methyl stretching vibrations) occur. In consonance with the X-ray data [2], the IR spectrum of crystalline $\mathbf{C A}$ shows the broad band about $3000 \mathrm{~cm}^{-1}$, characteristic of the $\nu \mathrm{O}-\mathrm{H}$ stretching mode of hydrogen bonded $\mathrm{O}-\mathrm{H}$ groups forming a cyclic dimeric structure
[12]. This band partially obscures the IR bands due to the $\nu \mathrm{CH}$ stretching modes, which in turn are clearly observable in the Raman spectrum of the crystal. By taking into consideration the data previously obtained for the monomer [1], the assignment of the $\nu \mathrm{CH}$ vibrations in the dimer is straightforward, since these modes do not experience significant shifts upon dimer formation. In addition, they appear at nearly equal frequencies to the corresponding bands observed for crystalline methyl trans-crotonate and methyl- $d_{3}$ transcrotonate $\quad\left(\nu \mathrm{C}_{\alpha}-\mathrm{H}, \quad 3054 \mathrm{~cm}^{-1} ; \quad \nu \mathrm{C}_{3}-\mathrm{H}\right.$, $3032 \mathrm{~cm}^{-1} ; \nu \mathrm{CH}_{3}$ as., 2982 and $2943 \mathrm{~cm}^{-1} ; \nu \mathrm{CH}_{3}$ s., $2918 \mathrm{~cm}^{-1}$; Raman data [13]).

As can be easily anticipated and in agreement with the results of calculations (see Table 3), all observed $\nu \mathrm{CH}$ stretching modes of the dimer were found to have almost coincident IR and Raman frequencies. Indeed, the theoretical predictions (scaled frequencies calculated at both the 6-31G* and AM1 levels of theory) agree fairly well with the experimental results, with the exception of the $\nu \mathrm{O}-\mathrm{H}$ stretching mode, which is predicted to occur at considerably higher frequencies, particularly in the AMI calculations. Such results are, however, casily explained by considering that (i) the strength of the intra-dimer hydrogen bonding is underestimated by the calculations and (ii) interdimer contacts certainly also play a relevant role in reducing the force constant of the $\mathrm{O}-\mathrm{H}$ bonds, thus leading to reduced vibrational $\nu \mathrm{O}-\mathrm{H}$ frequencies. Note that in agreement with both the structural and energy data previously discussed, the underestimation of the strength of the intra-dimer hydrogen bonding should be particularly important in the case of the semiempirical calculations (see Table 1).

\section{2. $1800-1200 \mathrm{~cm}^{-1}$ region}

The $\nu \mathrm{C}=\mathrm{C}$ ethylenic stretching mode, the $\delta \mathrm{CH}$ bending vibrations $\left(\delta \mathrm{C}_{\alpha}-\mathrm{H}, \delta \mathrm{C}_{\beta}-\mathrm{H}\right.$ and the methyl bending modes) and the stretching modes involving predominantly the carbon-oxygen bonds give rise to bands appearing in this spectral region. The latter are $\nu \mathrm{C}=\mathrm{O}$ and the hybrid vibrations having appreciable contributions of both $\nu \mathrm{C}-\mathrm{O}$ and $\delta \mathrm{C}-\mathrm{O}-\mathrm{H}$ coordinates which are 
Table 3

Experimental and calculated vibrational wavenumbers and intensities for trans-crotonic acid dimer ${ }^{\mathrm{a}}$

\begin{tabular}{|c|c|c|c|c|c|c|c|c|c|c|c|c|}
\hline \multirow{2}{*}{$\begin{array}{l}\text { Approximate } \\
\text { Description }\end{array}$} & \multirow[t]{2}{*}{ Symmetry } & \multicolumn{3}{|l|}{ Exp. } & \multicolumn{3}{|c|}{ Calc. (AM1) } & \multicolumn{5}{|c|}{ Calc. $\left(6-31 G^{*}\right)$} \\
\hline & & $\nu^{\mathrm{b}}$ & $I_{\mathrm{IR}}{ }^{\mathrm{c}}$ & $I_{\mathrm{R}}^{\mathrm{c}}$ & $\nu^{\text {scaled d }}$ & $I_{\mathrm{IR}}{ }^{\mathrm{e}}$ & $\Delta \nu^{\mathrm{f}}$ & $\nu$ & $I_{\mathrm{IR}}{ }^{\mathrm{e}}$ & $I_{\mathrm{R}}^{\mathrm{e}}$ & $\nu^{\text {scaled } \mathrm{g}}$ & $\Delta \nu^{f}$ \\
\hline \multirow[t]{2}{*}{$\nu \mathrm{O}-\mathrm{H}$} & $\mathrm{B}_{\mathrm{u}}$ & $\approx 3000^{\mathrm{h}}$ & 46.5 & & 3530 & 29.5 & 530 & 3802 & 42.7 & & 3334 & 334 \\
\hline & $A_{g}$ & n.o. & & & 3519 & & & 3757 & & 30.6 & 3294 & \\
\hline \multirow{2}{*}{$\nu \mathrm{C}_{a}-\mathrm{H}$} & $B_{u}^{\circ}$ & 3063 & 0.6 & & 3075 & 3.7 & 12 & 3388 & 0.2 & & 3071 & 8 \\
\hline & $A_{g}$ & 3058 & & 2.6 & 3075 & & 17 & 3388 & & 7.1 & 3071 & 13 \\
\hline \multirow[t]{2}{*}{$\nu \mathrm{C}_{\beta}-\mathrm{H}$} & $\mathbf{B}_{\mathrm{u}}{ }^{\circ}$ & 3040 & 0.4 & & 3016 & 1.1 & -24 & 3370 & 0.1 & & 3055 & 15 \\
\hline & $A_{g}$ & 3039 & & 8.4 & 3016 & & -23 & 3370 & & 7.1 & 3055 & 16 \\
\hline \multirow[t]{2}{*}{$\nu \mathrm{CH}_{3}$ as. } & $\mathbf{B}_{\mathrm{u}}$ & 2984 & 0.9 & & 2990 & 0.2 & 6 & 3288 & 0.7 & & 2982 & -2 \\
\hline & $\mathbf{A}_{\mathrm{g}}$ & 2978 & & 6.1 & 2990 & & 12 & 3288 & & 10.4 & 2982 & 4 \\
\hline \multirow{2}{*}{$\nu \mathrm{CH}_{3}$ as. } & $A_{u}$ & 2957 & 0.6 & & 2958 & 0.4 & 1 & 3253 & 0.8 & & 2966 & 9 \\
\hline & $\mathbf{B}_{\mathbf{g}}$ & 2957 & & 6.2 & 2958 & & 1 & 3253 & & 10.3 & 2966 & 9 \\
\hline \multirow{2}{*}{$\nu \mathrm{CH}_{3} \mathrm{~s}$} & $\mathbf{B}_{\mathrm{u}}$ & 2926 & 1.1 & & 2929 & 0.3 & 3 & 3202 & 0.9 & & 2904 & -22 \\
\hline & $A_{g}$ & 2925 & & 21.7 & 2929 & & 4 & 3202 & & 27.3 & 2904 & -21 \\
\hline \multirow[t]{2}{*}{$\nu \mathrm{C}=\mathrm{O}$} & $\mathbf{B}_{\mathbf{u}}$ & 1703 & 10.9 & & 1745 & 18.6 & 42 & 1963 & 13.7 & & 1734 & 31 \\
\hline & $A_{g}$ & 1694 & & 1.9 & 1733 & & 39 & 1925 & & 1.1 & 1700 & 6 \\
\hline \multirow[t]{2}{*}{$\nu \mathrm{C}=\mathrm{C}$} & $\mathbf{B}_{\mathbf{u}}^{\circ}$ & $1654^{i}$ & 8.0 & & 1667 & 6.7 & 13 & 1878 & 8.1 & & 1660 & 6 \\
\hline & $A_{g}$ & 1657 & & 17.2 & 1668 & & 11 & 1883 & & 16.2 & 1664 & 7 \\
\hline \multirow[t]{2}{*}{$\nu \mathrm{C}-\mathrm{O}+\delta \mathrm{C}-\mathrm{O}-\mathrm{H}$} & $\mathbf{B}_{\mathrm{u}}^{8}$ & 1449 & 2.7 & & 1351 & 5.1 & -98 & 1580 & 5.9 & & 1400 & -49 \\
\hline & $A_{g}$ & n.o. & & & 1349 & & & 1600 & & 1.8 & 1418 & \\
\hline \multirow[t]{2}{*}{$\delta \mathrm{CH}_{3}$ as. } & $\mathrm{A}_{\mathrm{g}}$ & 1443 & & 3.4 & 1449 & & 6 & 1631 & & 3.8 & 1445 & 2 \\
\hline & $\mathrm{B}_{\mathrm{u}}$ & 1442 & 0.9 & & 1449 & 0.6 & 7 & 1630 & 1.7 & & 1444 & 2 \\
\hline \multirow[t]{2}{*}{$\delta \mathrm{CH}_{3}$ as. } & $\mathrm{B}_{\mathrm{g}}$ & 1429 & & 2.8 & 1436 & & 7 & 1623 & & 2.5 & 1434 & 5 \\
\hline & $A_{u}$ & 1421 & 1.3 & & 1436 & 0.3 & 14 & 1623 & 0.2 & & 1434 & 13 \\
\hline \multirow[t]{2}{*}{$\delta \mathrm{CH}_{3} \mathrm{~s}$} & $\mathrm{~A}_{\mathrm{g}}$ & 1384 & & 3.2 & 1374 & & -10 & 1565 & & 1.7 & 1387 & 3 \\
\hline & $\mathrm{B}_{\mathrm{u}}$ & 1380 & 0.9 & & 1374 & 0.2 & -6 & 1565 & 0.1 & & 1387 & 7 \\
\hline$\delta \mathrm{C}-\mathrm{O}-\mathrm{H}+\nu \mathrm{C}-\mathrm{O}$ & $\mathrm{B}_{\mathrm{u}}$ & 1315 & 5.3 & & 1169 & 16.6 & -146 & 1374 & 6.7 & & 1221 & -94 \\
\hline & $A_{\mathrm{g}}$ & $131 \mathrm{I}^{\mathrm{j}}$ & & 1.0 & 1165 & & -146 & 1369 & & 0.6 & 1217 & -94 \\
\hline$\delta \mathrm{C}_{\beta^{-}-\mathrm{H}}$ & $\mathrm{B}_{\mathrm{u}}$ & 1295 & 2.8 & & 1307 & 0.1 & 12 & 1444 & 0.9 & & 1282 & 13 \\
\hline & $A_{g}$ & 1291 & & 3.7 & 1307 & & 16 & 1444 & & 3.8 & 1282 & -9 \\
\hline$\delta \mathbf{C}_{\alpha}-\mathbf{H}$ & $\mathbf{B}_{u}$ & 1224 & 4.4 & & 1275 & 0.3 & 51 & 1455 & 5.6 & & 1292 & 68 \\
\hline & $A_{g}$ & 1220 & & 1.4 & 1275 & & 55 & 1466 & & 1.5 & 1301 & 81 \\
\hline$\gamma \mathrm{CH}_{3}$ & $A_{g}$ & 1107 & & 0.7 & 1092 & & -15 & 1220 & & 0.7 & 1087 & -20 \\
\hline & $\mathbf{B}_{\mathrm{u}}$ & 1104 & 0.9 & & 1092 & 0.7 & -12 & 1221 & 0.2 & & 1088 & -16 \\
\hline$\gamma \mathrm{CH}_{3}+\gamma \mathrm{C}_{\beta}-\mathrm{H}$ & $A_{u}$ & 1052 & 0.3 & & 1064 & $<0.1$ & 12 & 1203 & 0.1 & & 1064 & 12 \\
\hline & $\mathbf{B}_{\mathrm{g}}$ & 1047 & & 1.0 & 1064 & & 17 & 1203 & & 0.4 & 1064 & 17 \\
\hline$\nu \mathrm{C}-\mathrm{C}$ & $A_{g}$ & 996 & & 1.0 & 972 & & -24 & 1072 & & 0.4 & 958 & -38 \\
\hline & $\mathbf{B}_{\mathrm{u}}$ & 987 & 0.3 & & 972 & $<0.1$ & -15 & 1071 & $<0.1$ & & 958 & -29 \\
\hline$\gamma \mathrm{C}_{\alpha}-\mathrm{H}$ & $\mathrm{B}_{\mathrm{g}}$ & 967 & & 0.3 & 976 & & 9 & 1108 & & $<0.1$ & 980 & 13 \\
\hline & $A_{u}$ & 963 & 3.5 & & 976 & 4.9 & 13 & 1108 & 1.2 & & 980 & 17 \\
\hline$\nu \mathrm{C}_{\alpha}-\mathrm{C}$ & $\mathbf{B}_{u}$ & 921 & 1.2 & & 890 & 0.2 & -31 & 988 & 0.8 & & 885 & -36 \\
\hline & $A_{g}$ & 918 & & 0.6 & 891 & & -27 & 988 & & 0.3 & 885 & -33 \\
\hline$\tau \mathrm{C}-\mathrm{O}+\gamma \mathrm{C}=\mathrm{O}$ & $A_{u}$ & 905 & 1.1 & & 704 & 4.4 & -201 & 982 & 5.8 & & 869 & -36 \\
\hline & $\mathrm{B}_{\mathrm{g}}$ & 902 & & 0.7 & 693 & & -209 & 962 & & 1.7 & 851 & -51 \\
\hline$\gamma \mathrm{C}_{3}-\mathrm{H}+\gamma \mathrm{CH}_{3}$ & $A_{u}$ & 844 & 0.9 & & 841 & $<0.1$ & -3 & 947 & 0.6 & & 838 & -6 \\
\hline & $\mathrm{B}_{\mathrm{g}}$ & 843 & & 2.2 & 841 & & -2 & 910 & & 0.5 & 805 & -38 \\
\hline$\delta \mathrm{C}=\mathrm{C}-\mathrm{O}$ & $\mathbf{B}_{\mathrm{u}}$ & 703 & 2.0 & & 646 & 2.4 & -57 & 752 & 1.7 & & 680 & -23 \\
\hline & $A_{y}$ & 685 & & 4.3 & 649 & & -36 & 742 & & 0.4 & 671 & -14 \\
\hline$\gamma \mathbf{C}=\mathbf{O}+\tau \mathrm{C}-\mathrm{O}$ & $\mathrm{B}_{\mathrm{g}}$ & 674 & & 0.5 & 600 & & -74 & 765 & & 0.3 & 677 & 3 \\
\hline & $A_{u}^{\circ}$ & n.o. & & & 617 & 2.5 & & 760 & $<0.1$ & & 673 & \\
\hline$\delta \mathrm{C}-\mathrm{C}=\mathrm{O}$ & $\mathbf{B}_{\mathrm{u}}$ & 519 & 0.9 & & 483 & 0.3 & -36 & 540 & 0.5 & & 496 & -23 \\
\hline & $A_{g}$ & 488 & & 3.2 & 475 & & -13 & 523 & & 0.3 & 481 & -7 \\
\hline
\end{tabular}


better described as $\nu \mathrm{C}-\mathrm{O}+\delta \mathrm{C}-\mathrm{O}-\mathrm{H}$ and $\delta \mathrm{C}-\mathrm{O}-$ $\mathrm{H}+\nu \mathrm{C}-\mathrm{O}[1]$.

In the IR spectrum of the monomer isolated in an $\mathrm{Ar}$ matrix [1], $\nu \mathrm{C}=\mathrm{O}, \nu \mathrm{C}-\mathrm{O}+\delta \mathrm{C}-\mathrm{O}-\mathrm{H}$ and $\delta \mathrm{C}-\mathrm{O}-\mathrm{H}+\nu \mathrm{C}-\mathrm{O}$ give rise to bands at 1757 , 1359 and $1147 \mathrm{~cm}^{-1}$ (see Table 2). The presence of hydrogen bonding in the dimer leads to more similar $\mathrm{CO}$ bonds. Hence, in crystalline $\mathbf{C A}$, the carbonyl stretching frequency must appear red shifted, while the frequencies associated with both the $\quad \nu \mathrm{C}-\mathrm{O}+\delta \mathrm{C}-\mathrm{O}-\mathrm{H}$ and $\delta \mathrm{C}-\mathrm{O}-\mathrm{H}+\nu \mathrm{C}-\mathrm{O}$ modes must increase. This prediction is reinforced by the results of the calculations which clearly point to an increase in the $\nu \mathrm{C}=\mathrm{O}$ frequency upon dimer formation $\left(6-31 \mathrm{G}^{*} . \Delta \nu_{\text {dimer-monomer }}=\right.$ $\left.-40 \mathrm{~cm}^{-1}\right)$ and a decrease in the frequencies of both $\nu \mathrm{C}-\mathrm{O}+\delta \mathrm{C}-\mathrm{O}-\mathrm{H}$ and $\delta \mathrm{C}-\mathrm{O}-\mathrm{H}+\nu \mathrm{C}-\mathrm{O}$ (6-31G*: $\Delta \nu_{\text {dimer-monomer }}=40 \mathrm{~cm}^{-1}$ and $52 \mathrm{~cm}^{-1}$, respectively). In addition, since the calculations underestimate the consequences of the

Table 3 Continued

\begin{tabular}{|c|c|c|c|c|c|c|c|c|c|c|c|c|}
\hline \multirow{2}{*}{$\begin{array}{l}\text { Approximate } \\
\text { Description }\end{array}$} & \multirow[t]{2}{*}{ Symmetry } & \multicolumn{3}{|l|}{ Exp. } & \multicolumn{3}{|c|}{ Calc. (AM1) } & \multicolumn{5}{|c|}{ Calc. $\left(6-31 G^{*}\right)$} \\
\hline & & $\nu^{b}$ & $I_{\mathrm{IR}}{ }^{\mathrm{c}}$ & $I_{\mathrm{R}}{ }^{\mathrm{c}}$ & $\nu^{\text {scaled d }}$ & $I_{\mathrm{IR}} \mathrm{e}$ & $\Delta \nu^{r}$ & $\nu$ & $I_{1 \mathrm{R}}{ }^{\mathrm{e}}$ & $I_{\mathrm{R}}{ }^{\mathrm{e}}$ & $\nu^{\text {scaled d }}$ & $\Delta \nu^{\mathrm{f}}$ \\
\hline \multirow[t]{2}{*}{$\delta \mathrm{C}-\mathrm{C}_{\beta}=\mathrm{C}$} & $A_{g}$ & 417 & & 2.9 & 403 & & -14 & 439 & & 0.5 & 408 & -9 \\
\hline & $\mathbf{B}_{u}$ & 402 & 0.4 & & 394 & 0.6 & -8 & 425 & 0.3 & & 396 & -6 \\
\hline \multirow[t]{2}{*}{$\delta \mathrm{C}=\mathrm{C}_{\alpha}-\mathrm{C}$} & $\mathrm{B}_{\mathrm{u}}$ & 256 & 1.2 & & 246 & 0.4 & -10 & 260 & 0.5 & & 252 & -4 \\
\hline & $A_{g}$ & 238 & & 0.4 & 210 & & -28 & 239 & & $<0.1$ & 234 & -4 \\
\hline \multirow[t]{2}{*}{$\tau \mathrm{C}=\mathrm{C}$} & $\mathrm{B}_{\mathrm{g}}$ & 231 & & 0.5 & 202 & & -29 & 231 & & $<0.1$ & 206 & -25 \\
\hline & $A_{u}^{B}$ & n.o. & & & 200 & $<0.1$ & & 223 & $<0.1$ & & 199 & \\
\hline \multirow[t]{2}{*}{$\tau \mathrm{C}-\mathrm{C}$} & $\mathrm{B}_{\mathrm{g}}$ & 194 & & 0.4 & 187 & & -7 & 218 & & 0.4 & 195 & 1 \\
\hline & $\mathrm{A}_{\mathrm{u}}$ & n.o. & & & 187 & $<0.1$ & & 214 & $<0.1$ & & 191 & \\
\hline \multirow[t]{2}{*}{$\tau \mathrm{C}_{r x}-\mathrm{C}$} & $A_{u}$ & n.o. & & & 105 & 0.1 & & 124 & $<0.1$ & & 112 & \\
\hline & $\mathrm{B}_{\mathrm{g}}$ & 125 & & 1.2 & 101 & & -24 & 123 & & 0.3 & 111 & -14 \\
\hline \multirow[t]{2}{*}{$\nu \mathrm{O} \cdots \mathrm{H}$} & $A_{g}$ & 140 & & 0.2 & $(121)$ & & -19 & 144 & & 0.1 & 151 & 11 \\
\hline & $\mathrm{B}_{\mathrm{u}}$ & n.o. & & & $(58)$ & 0.1 & & 70 & 0.1 & & 87 & \\
\hline$\delta$ ring $g_{(\text {implane })}$ & $A_{g}$ & n.o. & & & $(50)$ & & & 102 & & 0.1 & 114 & \\
\hline \multirow{3}{*}{$\delta$ ring $($ out-of-plane $)$} & $\mathrm{B}_{\mathrm{g}}$ & n.o. & & & $(38)$ & & & 69 & & 0.2 & 63 & \\
\hline & $A_{u}$ & n.o. & & & (32) & $<0.1$ & & 56 & $<0.1$ & & 52 & \\
\hline & $\mathbf{A}_{u}$ & n.o. & & & $(10)$ & 0.1 & & 23 & $<0.1$ & & 23 & \\
\hline
\end{tabular}

${ }^{a}$ Wavenumbers in $\mathrm{cm}^{-1} ; \nu$, stretching; $\delta$, bending; $\omega$, wagging; $\gamma$, rocking; $\tau$, torsion; n.o., not observed; s., symmetric; as., asymmetric.

${ }^{b}$ Wavenumbers reported for both $A_{g}$ and $B_{g}$ symmetry vibrations are observed in the Raman spectrum while those correspondent to $A_{u}$ and $B_{u}$ vibrations are observed in the IR spectrum. However, some bands are observed in both spectra, due to the break down of the symmetry selection rules usually observed in hydrogen-bonded compounds (see text).

${ }^{c}$ Experimental IR and Raman intensities presented are normalised values to the total intensity of all observed bands $\left(I=100 \times I^{\mathrm{Obs}} / \Sigma_{i=1, n} I_{i}^{\mathrm{Obs}}\right.$, where $n$ is the number of observed bands ascribed to the dimer); except for a few bands which show a very broad profile (where approximate integral intensities are reported), all intensities reported correspond to peak intensities. Values in italic are those considered to be affected by a larger error, due to partial overlap of the associated band with a different band of higher or similar intensity.

${ }^{\mathrm{d}} \nu^{\text {scaled }}$ correspond to AM1 calculated wavenumbers corrected by adding the $\Delta \nu$ values previously obtained for the monomeric species (see Table 2). Since no $\Delta \nu$ values can be obtained for some vibrations of the dimer from the calculated wavenumbers of the monomer, some wavenumbers presented in this Table are uncorrected values; these are shown in parentheses.

${ }^{\mathrm{C}}$ Calculated intensities are normalized values to the total calculated intensity of all bands which have an experimentally observed counterpart. The non-normalized infrared intensities $\left(\mathrm{km} \mathrm{mol}^{-1}\right)$ can be obtained by multiplying the values presented in the Table by 60.2 (AM1) or $32.9\left(6-31 \mathrm{G}^{*}\right)$. The non-normalized Raman scattering activities $\left(\AA \mathrm{amu}^{-1}\right)$ can be obtained by multiplying the values presented in the Table by $13.9\left(6-31 \mathrm{G}^{*}\right)$.

f $\Delta \nu=\nu^{\text {obs. }}-\nu^{\text {scaled }}$.

gs for the monomer, an additional correction factor (1.033) was also applied to the resulting scaled ab initio $\mathrm{C}-\mathrm{H}$ stretching wavenumbers of the dimer.

h Very broad band; the value presented corresponds to the approximate maximum wavenumber.

'A second band, due to Fermi resonance, is observed at $1637 \mathrm{~cm}^{-1}$.

${ }^{j}$ A second band, due to Fermi resonance, is observed at $1287 \mathrm{~cm}^{-1}$. 
intra-dimer hydrogen bonding and do not take into consideration inter-dimer interactions, the calculated frequency shifts are lower limit values for the observed shifts. The $\nu \mathrm{C}=\mathrm{O}$ out-of-phase $\left(\mathrm{B}_{\mathrm{u}}\right.$ symmetry) IR band gives rise to the intense band at $1703 \mathrm{~cm}^{-1}$. This band shows a shoulder which may be assigned to the $\nu \mathrm{C}=\mathrm{O}$ in-phase $\left(\mathrm{A}_{\mathrm{g}}\right.$ symmetry) vibration, giving rise to the Raman band at ca. $1694 \mathrm{~cm}^{-1}$ (partially underneath the intense Raman band due to the $\mathrm{A}_{\mathrm{g}} \nu \mathrm{C}=\mathrm{C}$ mode at $1657 \mathrm{~cm}^{-1}$ ). As mentioned above, the appearance of the $\nu \mathrm{C}=\mathrm{O}$ in-phase the IR spectrum is a consequence of the usual breakdown of the general vibrational selection rules in hydrogen-bonded systems (relatively weakly coupled systems) $[1,11]$. In the IR spectrum of the crystal, $\nu \mathrm{C}-\mathrm{O}+\delta \mathrm{C}-\mathrm{O}-\mathrm{H}$ and $\delta \mathrm{C}-\mathrm{O}-\mathrm{H}+\nu \mathrm{C}-\mathrm{O}$ give rise to the bands at 1449 and $1315 \mathrm{~cm}^{-1}$, respectively. In the Raman spectrum, in turn, only the band due to the $\mathrm{A}_{\mathrm{g}}$ (Raman active) $\delta \mathrm{C}-\mathrm{O}-\mathrm{H}+\nu \mathrm{C}-\mathrm{O}$ mode could be observed (as a Fermi doublet with components at 1311 and $1287 \mathrm{~cm}^{-1}$ resulting from the interaction with the first overtone of the $\delta \mathrm{O}=\mathrm{C}-\mathrm{O} \mathrm{A}$ mode, whose fundamental vibration occurs at $685 \mathrm{~cm}^{-1}$ ). The band due to the $\mathrm{A}_{\mathrm{g}} \nu \mathrm{C}-\mathrm{O}+\delta \mathrm{C}-\mathrm{O}-\mathrm{H}$ vibration could not be observed, certainly being obscured by the band at $1443 \mathrm{~cm}^{-1}$ due to a methyl bending mode $\left(\delta \mathrm{CH}_{3}\right.$ as $\left.\mathrm{A}_{\mathrm{g}}\right)$.

The remaining modes giving rise to bands in this spectral region should not be considerably affected by dimer formation. Thus, all but the bands due to the $\delta \mathrm{C}_{\alpha}-\mathrm{H}$ bending modes appear at the same frequency in the spectra of crystalline and matrix isolated CA (in the Raman spectrum of the crystal, $\nu \mathrm{C}=\mathrm{C} \Lambda_{\mathrm{g}}$ appears as a Fermi doublet at 1657 and $1637 \mathrm{~cm}^{-1}$, most probably due to the interaction of this fundamental with the first overtone of the $\gamma \mathrm{C}_{\beta}-\mathrm{H}+\gamma \mathrm{CH}_{3} \quad \mathrm{~B}_{\mathrm{g}}$ rocking mode whose fundamental appears at $843 \mathrm{~cm}^{-1}$ ). When compared with the frequency observed for the monomer $\left(1271 \mathrm{~cm}^{-1}[1]\right), \delta \mathrm{C}_{\alpha}-\mathrm{H}$ appear considerably red shifted in the spectra of crystalline CA. Very interestingly, the calculations predict that a blue shift should occur in this mode upon dimer formation (see Tables 2, 3). The observed red shift must then be ascribed to inter-dimer contacts and thus the spectroscopic results are in consonance with X-ray data [2-4], revealing the existence in the crystalline $\mathrm{CA}$ of an inter-dimer $\mathrm{C}_{\alpha}-\mathrm{H} \cdots \mathrm{O}=$ hydrogen bond. Unfortunately the frequency of the $\nu \mathrm{C}_{\alpha}-\mathrm{H}$ stretching mode in the monomer is not precisely known since the band due to this mode could not be observed in the matrix isolated study of monomeric CA [1], and no comparison can be made between the frequencies of this vibration in the monomer and in crystalline $\mathbf{C A}$, in order to obtain further spectroscopic support to the existence of this inter-dimer $\mathrm{C}_{\alpha}-\mathrm{H} \cdots \mathrm{O}=$ contact in crystalline $\mathbf{C A}$.

\section{3. $1200-700 \mathrm{~cm}^{-1}$ region}

In this spectral region, the bands due to the $\nu \mathrm{C}-\mathrm{C}$ stretching modes appear, as well as the $\gamma \mathrm{CH}_{3}$ and $\gamma \mathrm{C}-\mathrm{H}$ rocking vibrations $\left(\gamma \mathrm{C}_{\alpha} \mathrm{H}\right.$, $\gamma \mathrm{C}_{\beta}-\mathrm{H}$ - which considerably mixes the $\gamma \mathrm{CH}_{3}$ rocking modes of the same symmetry) and the $\tau \mathrm{C}-\mathrm{O}+\gamma \mathrm{C}=\mathrm{O}$ hybrid vibration with significant contributions of both $\tau \mathrm{C}-\mathrm{O}$ and $\gamma \mathrm{C}=\mathrm{O}$ oscillators.

The assignment of the rocking modes in the crystalline phase spectra of CA is not difficult to undertake, since no pronounced shifts upon dimer formation are observed (see Tables 2, 3). The fact that the $\gamma \mathrm{CH}_{3}+\gamma \mathrm{C}_{\beta}-\mathrm{H} \mathrm{A}^{\prime \prime}$ mode of the monomer has not been observed previously [1] could be easily overcome by taking into consideration the available data on crystalline methyl crotonate and methyl- $d_{3}$ crotonate, where the vibration occurs at ca. $1054 \mathrm{~cm}^{-1}$ and $1047 \mathrm{~cm}^{-1}$, respectively in the IR and Raman spectra [13]. The assignment of the $\nu \mathrm{C}-\mathrm{C}$ stretching modes is more difficult, since these vibrations are usually quite sensitive to the chemical environment. The calculations predict that these vibrations should have higher frequencies in the dimer than in the monomer, and the assignments made in this study are in agreement with these results. Indeed, it was found that all $\nu \mathrm{C}-\mathrm{C}$ stretching modes (either $\nu \mathrm{C}-\mathrm{C}$ or $\nu \mathrm{C}_{\alpha}-\mathrm{C}$ ) blue shift even more than predicted by the calculations, showing that crystal packing imposes an additional resistance to the stretching of the different $\mathrm{C}-\mathrm{C}$ bonds of the dimeric unit.

In matrix-isolated monomeric CA, the IR bands appearing at 699 and $566 \mathrm{~cm}^{-1}$ were assigned to the $\gamma \mathrm{C}=\mathrm{O}$ rocking and $\tau \mathrm{C}-\mathrm{O}$ torsional vibrations [1]. 
However, in the dimer, these coordinates mix extensively and it is preferable to consider hybrid coordinates $(\tau \mathrm{C}-\mathrm{O}+\gamma \mathrm{C}=\mathrm{O}$ and $\gamma \mathrm{C}=\mathrm{O}+\tau \mathrm{C}-\mathrm{O})$ instead of the pure rocking and torsional modes. The higher frequency modes were predicted both to have slightly higher contributions of the torsional vibration [14] and to be strongly blue shifted (6-31G*: $\Delta \nu_{\text {dimer-monomer }} \approx 160 \mathrm{~cm}^{-1}$ ) and thus, the bands at $905 \mathrm{~cm}^{-1}$ (IR) and $902 \mathrm{~cm}^{-1}$ (Raman) are ascribed to the $\tau \mathrm{C}-\mathrm{O}+\gamma \mathrm{C}=\mathrm{O} \mathrm{A}_{\mathrm{u}}$ and $\mathrm{B}_{\mathrm{g}}$ modes, respectively. The fact that the observed blue shifts are considerably larger than the predicted ones can be ascribed again to underestimation by the calculations of the strength of the intra-dimer hydrogen bonding as well as to the existence in the crystal of inter-dimer crystal packing forces (not considercd by the calculations). Note that both intra-dimer hydrogen bonding and inter-dimer contacts should considerably restrict the movements of the hydroxyl hydrogen atoms, in particular their out-of-plane movements, thus leading to an increase in the force constants associated with these modes and, consequently, to a frequency shift to higher values. A similar blue shift upon going from the matrix-isolated molecule to the crystalline state was also observed previously for the same vibrations in acrylic acid [15].

\subsection{Region below $700 \mathrm{~cm}^{-1}$}

In this spectral region appear the bands due to the skeletal bending modes $(\delta \mathrm{O}=\mathrm{C}-\mathrm{O}$, $\gamma \mathrm{C}=\mathrm{O}+\tau \mathrm{C}-\mathrm{O}, \quad \delta \mathrm{C}-\mathrm{C}=\mathrm{O}, \quad \delta \mathrm{C}=\mathrm{C}_{\alpha}-\mathrm{C}, \quad \delta \mathrm{C}-$ $\left.\mathrm{C}_{\beta}=\mathrm{C}\right)$ and torsions $\left(\tau \mathrm{C}=\mathrm{C}, \tau \mathrm{C}-\mathrm{C}, \tau \mathrm{C}_{\alpha}-\mathrm{C}\right)$. In addition, the $\nu \mathrm{O} \cdots \mathrm{H}$ stretching modes and the ring bending modes related with the hydrogen bonds of the dimer also should give rise to bands in the region. However, we were not able to study the IR spectra below $250 \mathrm{~cm}^{-1}$ or approach closer to $100 \mathrm{~cm}^{-1}$ to the excitation line in the Raman experiments, and thus bands due to the lowest frequency modes could not be observed.

In the case of the matrix-isolated monomer of CA, the IR spectrum shows only three bands in this spectral region $\left(\delta \mathrm{O}=\mathrm{C}-\mathrm{O}, 648 \mathrm{~cm}^{-1}\right.$; $\gamma \mathrm{C}=\mathrm{O}+\tau \mathrm{C}-\mathrm{O}, 566 \mathrm{~cm}^{-1} ; \delta \mathrm{C}-\mathrm{C}=\mathrm{O}, 466 \mathrm{~cm}^{-1}$ [1]). These bands have counterparts in the Raman spectrum of the crystalline $\mathbf{C A}$ at 685,674 and
$688 \mathrm{~cm}^{-1}$, respectively. In the IR spectrum, $\delta \mathrm{O}=\mathrm{C}-\mathrm{O}$ and $\delta \mathrm{C}-\mathrm{C}=\mathrm{O}$ give rise to the bands at 703 and $519 \mathrm{~cm}^{-1}$, while the band due to the $\gamma \mathrm{C}=\mathrm{O}+\tau \mathrm{C}-\mathrm{O}$ vibration could not be observed (the $\delta \mathrm{C}-\mathrm{C}=\mathrm{O} \mathrm{B}_{\mathrm{u}}$ mode, which gives rise to the intense IR band at $703 \mathrm{~cm}^{-1}$, also produces the low intensity Raman band at $698 \mathrm{~cm}^{-1}$ ). Thus, all the threc bending modes, $\delta \mathrm{O}=\mathrm{C}-\mathrm{O}, \gamma \mathrm{C}=\mathrm{O}+$ $\tau \mathrm{C}-\mathrm{O}$ and $\delta \mathrm{C}-\mathrm{C}=\mathrm{O}$, were found to increase their frequency on going from the matrix-isolated to crystalline CA. Indeed, these results agree with the theoretical predictions, which clearly show that these vibrations blue shift upon dimer formation (see Tables 2, 3). As expected, the predicted frequency shifts are better reproduced by $6-31 \mathrm{G}^{*}$ than by AM 1 calculations. The latter show a fair fitting to the experimental values, indicating that the observed shifts in the vibrations considered are not strongly affected by inter-dimer crystal packing interactions, but predominantly by intradimer hydrogen-bonding (and strict geometrical changes in the $\mathrm{C}-\mathrm{C}(=\mathrm{O})-\mathrm{O}-\mathrm{H}$ moiety $)$.

The remaining bands observed in this spectral region are easily assigned taking into consideration the theoretical results. As anticipated, both the $\delta \mathrm{C}=\mathrm{C}_{\alpha}-\mathrm{C}$ and $\delta \mathrm{C}-\mathrm{C}_{\beta}=\mathrm{C}$ modes seem to be almost unaffected by the inter-dimer crystal packing forces (the calculated values for the dimer fit very well the observed frequencies observed experimentally for CA in the crystalline phase), while most of the observed torsional modes are found to have slightly higher frequencies than those predicted for the dimer, showing the greater sensitivity of these vibrations to the crystal packing interactions which tend to restrict the large amplitude torsional vibrations.

\section{Acknowledgements}

The author thanks Prof. Mozart N. Ramos and Mr João Bosco P. da Silva, Departamento de Química Fundamental, Universidade Federal de Pernambuco, Recife PE, Brasil, for their interest in this work and help in part of the calculations, and acknowledge financial support from Junta Nacional de Investigação Científica e Tecnológica (J.N.I.C.T.), Portugal. 


\section{References}

[1] R. Fausto, A. Kulbida and O. Schrems, J. Chem. Soc. Faraday Trans., 91 (1995) 3755.

[2] L. Leiserowitz, Acta Cryst., B32 (1996) 775.

[3] S. Block, S.E. Filippakis and G.M.J. Schmidt, J. Chem. Soc., B (1967) 233.

[4] Y. Chatani, Y. Sakate and I. Nitta, Polymer, Lett., l (1963) 419.

[5] J.L.H. Allan, G.D. Meakins and M.C. Whiting, J. Chem. Soc., (1955) 1874

[6] J.R. Cowles, W.O. George and W.G. Fateley, J. Chem. Soc. Perkin II (1975) 396.

[7] W.J. Hehre, R. Ditchefield and J.A. Pople, J. Chem. Phys., 56 (1972) 2257.

[8] M.J.S. Dewar, E.G. Zoebisch, E.F. Healy and J.J.P. Stewart, J. Am. Chem. Soc, 107 (1985) 3902

[9] M.J. Frisch, G.W. Trucks, H.B. Schlegel, P.M.W. Gill, B.G. Johnson, M.W. Wong. J.B. Foresman, M.A. Robb.
M. Head-Gordon, E.S. Replogle, R. Gomperts, J.L. Andres, K. Raghavachari, J.S. Binkley, C. Gonzalez, R.L. Martin, D.J. Fox, D.J. Defrees, J. Baker, J.J.P. Stewart and J.A. Pople, GAussinN 92/DFt (Revision G.2), Gaussian Inc., Pittsburgh PA, 1993.

[10] H.B. Schlegel, Ph.D. Thesis, Queen's University, Kingston, Ontario, Canada, 1975.

[11] W.R. Feairheller, Jr. and J.E. Katon, Spectrochim. Acta, A23 (1967) 2225.

[12] J.R. Barceló, M. Pilar-Jorge and C. Otero, J. Chem. Phys., 28 (1958) 1230

[13] M.D.G. Faria, J.J.C. Teixeira-Dias and R. Fausto, Vibrat. Spectrosc., 2 (1991) 107

[14] R. Fausto, unpublished results (available from the author upon request).

[15] A. Kulbida, M.N. Ramos, M. Rasanen, J. Nieminen, O. Schrems and R. Fausto, J. Chem. Soc. Faraday Trans., 91 (1995) 1571. 